\title{
Some early recollections of Raimond Castaing in microprobe analysis
}

I first put my school French to good use in 1953, when my research supervisor Ellis Cosslett gave me a copy of a thesis by one Raimond Castaing. His instructions were to read it thoroughly and to look in particular for any reference to scanning the electron probe. Fortunately I could find none, and so my project was decided : to build an instrument in which the sample could be imaged in a selected X-ray radiation, rather as a scanning electron microscope imaged the surface in secondary electrons. Oatley and McMullan in Cambridge had recently demonstrated the latter technique and I hoped to gain the necessary intensity for X-ray imaging by the use of magnetic lenses which were already in widespread use in Cosslett's laboratory. Everything else that a new research student needed to know about microprobe analysis seemed to be found in Castaing's thesis, which was to remain a reference work for me for many years to come.

In the following year 1954, Cosslett introduced me to Castaing in person, and I learned of his plans to build an instrument with a magnetic lens having a coaxial optical microscope to aim the probe and position it exactly at the focus of the spectrometer. This facility proved to be immediately attractive to the practising metallurgist, and some ioneering applications using point analysis were reported by Castaing, Philibert and Crussard in 1957. By that time our scanning instrument was operational, and, with the collaboration of David Melford at the laboratories of Tube Investments nearby, we were able to illustrate the value of imaging in metallurgy. For many years the argument continued about the benefits of one technique against the other, Castaing's lens being associated with a high-resolution crystal spectrometer for point analysis, while the scanning technique utilised a semi-focussing spectrometer for area mapping. Point analysis was then a subsidiary function. It was interesting to reflect later how the design of the two instruments was conditioned by the respective backgrounds in which they were conceived - with the emphasis on the electron optics in Cosslett's group, and on the crystallography in the early work of Castaing and Guinier.

When in the 1960's there were commercial instruments available of both types, there arose an increasing need for better quantitative analysis. The source book for much of the basic theory was still Castaing's thesis, supplemented by some classic measurements by Castaing and Descamps of the distribution of X-ray emission in depth below the sample surface. One factor that was lacking, however, was an understanding of the energy loss due to electrons backscattered from the sample. In 1960 Castaing started to investigate this effect and pointed the way towards a means for calculating the backscatter. I first learnt of this work in a conversation with him in April 1960, which remains in my memory as it took place in a car crossing Paris at high speed. 
Castaing was the driver, and found it necessary to use both hands to emphasise the beauty of the method! At the end of the journey my colleague in the rear set, David Melford, emerged white and shaken, but agreed with me that we had just made a giant step forward in our understanding of the problem. Fortunately digital computers were just becoming widely available to make the calculations practicable.

I met Castaing at intervals at various conferences during this period : notably in snowy Washington in 1958, sunny California in 1962, sticky Boston in 1963 and at an elegant chateau near Paris in 1965. These were formative years in the subject of microprobe analysis and all these meetings were marked by the liveliness and insight which Raymond Castaing brought to the occasion. There will be as many accounts of his contributions to science as there will be well wishers at his birthday commemoration. For myself I acknowledge with gratitude the seminal influence he had on my own endeavours, and I wish him many more happy and fruitful years to come.

Dr. Peter DUNCUMB FRS former Director and General Manager Tube Investments Research Laboratories Cambridge, UK. 
Experimental depth distribution curves of the total characteristic X-ray emission in various targets (including the secondary fluorescence emission excited by the continuous spectrum) obtained by a tracer technique, for a $29 \mathrm{keV}$ energy of the impinging electrons. CASTAING R. and DESCAMPS J., C.R.A.S. 238 (1954) 1506.

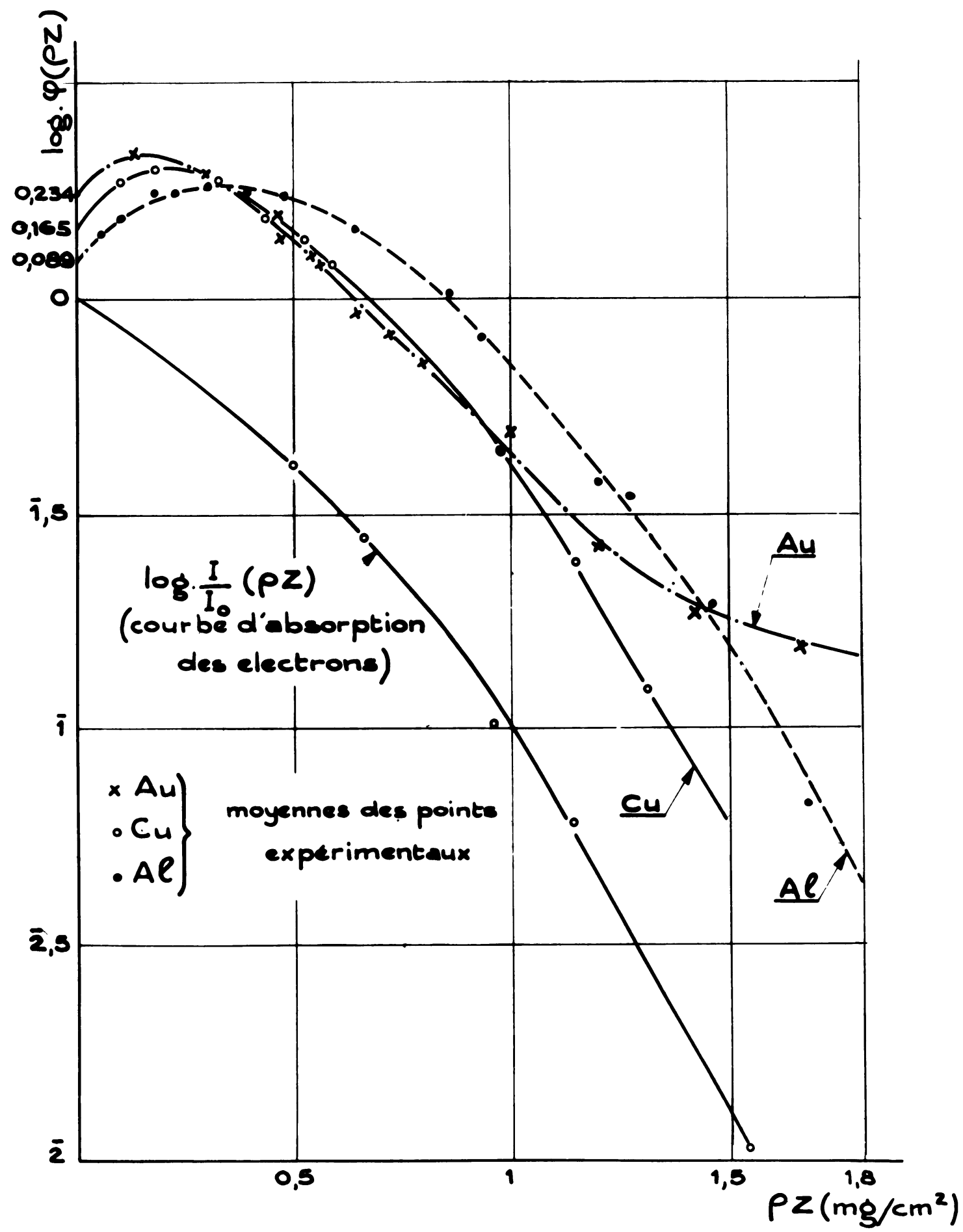

